\title{
Soroprevalência de Babesia bigemina em bovinos na mesorregião Norte Fluminense ${ }^{1}$
}

\author{
José Carlos P. Souza ${ }^{2}$, Cleber O. Soares ${ }^{2}$, Alessandra Scofield ${ }^{3}$, Claudio R. Madruga ${ }^{4}$, \\ Nathalie C. Cunha ${ }^{3}$, Carlos L. Massard ${ }^{2}$ e Adivaldo H. Fonseca ${ }^{2}$
}

\begin{abstract}
Souza J.C.P., Soares C.O., Scofield A., Madruga C.R., Cunha N.C., Massard C.L. \& Fonseca A.H. 2000. [Seroprevalence of Babesia bigemina in cattle in the "Norte Fluminense" mesoregion.] Soroprevalência de Babesia bigemina em bovinos na mesorregião Norte Fluminense. Pesquisa Veterinária Brasileira 20(1):26-30. Depto Parasitologia Animal, Univ. Fed. Rural do Rio de Janeiro, Km 47, Seropédica, RJ 23890-000, Brazil.

Serumprevalence of antibodies against Babesia bigemina were evaluated by the indirect Enzyme-Linked Immunosorbent Assay (ELISA). Sera samples from 532 bovines of nine municipalities in the "Norte Fluminense" mesoregion, Rio de Janeiro state, were analysed. The results showed that 371 (69.74\%) were positive by indirect ELISA, of which $32.33 \%$ were with a titre of $1: 500,22.56 \%$ of $1: 1000,10.90 \%$ of $1: 2000,3.38 \%$ of $1: 4000,0.38 \%$ of $1: 8000$, $0.19 \%$ of $1: 16000$, and $30.26 \%$ were negative. The prevalence analysis was done within three age groups: 1 to 3 years $(n=110), 3$ to 6 years $(n=241)$ and $>6$ years $(n=181)$, of which $73.64 \%, 69.30 \%$ and $67.95 \%$ were positive, respectively. According to the breed, $68.47 \%$ of beef cattle $(n=444)$ and $76.14 \%$ of dairy cattle $(n=88)$ were positive. Regarding the sex, $69.82 \%$ of the females $(n=497)$ and $68.57 \%$ of the males $(n=35)$ were positive. There were no significant differences between age groups, breeding types and sexes $(P>0.05)$. There were significant differences $(\mathrm{P}<0.0001)$ between the prevalence in the municipalities. The infection by $B$. bigemina in this mesoregion is heterogeneous, and the seroprevalence showed that the region has to be considered enzootically unstable. The epidemiological situation requires serological identification of exposed animals at risk condition for the control of babesiosis.
\end{abstract}

INDEX TERMS: Seroepidemiology, Babesia bigemina, bovine babesiosis, enzyme immunoassay, "Norte Fluminense" mesoregion, Brazil.

RESUMO.- Investigou-se a soroprevalência de anticorpos anti Babesia bigemina em bovinos de nove municípios na mesorregião Norte Fluminense, estado do Rio de Janeiro. Realizou-se o ensaio de imunoadsorção enzimática (ELISA) indireto em 532 amostras de soro de bovinos. A análise soroepidemiológica revelou que $371(69,74 \%)$ foram reagentes positivos ao ELISA indireto, dos quais: $32,33 \%$ com título de 1:500, 22,56\% com título de 1:1000, 10,90\% com título de

\footnotetext{
${ }^{1}$ Aceito para publicação em 13 de setembro de 1999.

${ }^{2}$ Curso de Pós-Graduação em Medicina Veterinária - Parasitologia Veterinária, Universidade Federal Rural do Rio de Janeiro (UFRRJ). Km 47, Seropédica, RJ 23890-000; e-mail: csoares@ufrrj.br

${ }^{3}$ Acadêmica de Medicina Veterinária da UFRRJ, Bolsista de Iniciação Científica / CNPq.

${ }^{4}$ Centro Nacional de Pesquisa de Gado de Corte, Embrapa, Campo Grande, MS.
}

1:2000, 3,38\% com título de $1: 4000,0,38 \%$ com título de $1: 8000,0,19 \%$ com título de $1: 16000$ e $30,26 \%$ foram negativos. A análise da prevalência segundo a faixa etária foi realizada dividindo-se em três grupos etários: 1 a 3 anos $(n=110)$, 3 a 6 anos $(n=241)$ e maior que 6 anos $(n=181)$, onde $73,64 \%$, $69,30 \%$ e $67,95 \%$ dos animais foram positivos, respectivamente. Segundo a aptidão zootécnica $68,47 \%$ dos bovinos com aptidão para corte $(n=444)$ e $76,14 \%$ dos bovinos com aptidão para leite $(n=88)$ foram positivos. Em relação ao sexo, $69,82 \%$ das fêmeas $(n=497)$ e $68,57 \%$ dos machos $(n=35)$ foram positivos. Não houve diferença significativa entre os grupos etários, entre as aptidões e entre os sexos $(\mathrm{P}>0,05)$. A prevalência entre os municípios diferiu significativamente $(\mathrm{P}<0,0001)$, demonstrando que a infecção por $B$. bigemina em bovinos não é homogênea na mesorregião. A soroprevalência encontrada caracteriza esta mesorregião como uma área de instabilidade enzoótica. Nesta circunstância epidemiológica justifica-se o controle da enfermidade com o 
acompanhamento sorológico para identificação dos animais expostos a condição de risco.

TERMOS DE INDEXAÇÃO: Soroepidemiologia, Babesia bigemina, babesiose bovina, ensaio imunoenzimático, mesorregião Norte Fluminense, Brasil.

\section{INTRODUÇÃO}

As babesioses bovina são enfermidades parasitárias, que nos países de clima tropical e subtropical, são causadas pelos hemoprotozoários Babesia bigemina (Smith \& Kilborne, 1893) e $B$. bovis (Babés, 1888). Estas são desencadeadas, principalmente, pela massiva destruição eritrocítica, decorrente dos aspectos biológicos dos agentes em realizarem parte de seu ciclo no interior destas células. B. bigemina, típico grande babesiídeo dos bovinos é transmitido por ninfas e adultos do carrapato Boophilus microplus. Este babesí́deo determina um quadro de anemia progressiva, palidez de mucosas, hemoglobinúria, febre e inapetência.

Em associação a $B$. microplus as babesioses bovina são responsáveis por prejuízos anuais na ordem de 1,0 bilhão de dólares para o Brasil (MARA 1985). A dinâmica da infecção por Babesia spp. é dependente de fatores como população de carrapatos infestantes; capacidade de transmissão do carrapato; susceptibilidade dos bovinos, que pode variar com a raça, idade, estado fisiológico e imunitário.

O estudo epidemiológico das babesioses bovina em uma determinada área pode revelar a possibilidade da ocorrência ou não de surtos. Tal possibilidade é avaliada segundo a situação epidemiológica que pode ser, principalmente, de três tipos: estabilidade enzoótica, instabilidade enzoótica e situação de área marginal (Mahoney 1975, Mahoney \& Ross 1972). As provas sorológicas são os métodos mais adequados e práticos para se conhecer a situação epidemiológica das babesioses, onde entre elas o ensaio imunoenzimático de adsorção (ELISA) é o que confere melhores resultados (Araújo et al. 1998).

O estado do Rio de Janeiro possui um rebanho bovino efetivo de 1.813.743 cabeças e, destes, aproximadamente, $28,6 \%$ encontram-se na mesorregião Norte Fluminense (CIDE 1997). A situação epidemiológica das babesioses bovina no estado não é conhecida. $O$ presente estudo teve por propósito investigar a soroprevalência de anticorpos anti $B$. bigemina em bovinos na mesorregião Norte Fluminense do estado do Rio de Janeiro.

\section{MATERIAL E MÉTODOS}

\section{Região estudada}

O estudo foi conduzido com amostras de soro de bovinos de nove municípios da mesorregião Norte Fluminense do estado do Rio de Janeiro, segundo divisão político-administrativa da Fundação CIDE. A população estimada de bovinos desta mesorregião é de 518.465 cabeças, em uma área total de 663.198 hectares com a produção de leite de 81.806 .000 litros anuais (CIDE 1997) (Quadro 1).

\section{Amostragem dos soros e divisão por grupos}

As amostras de soros foram colhidas aleatoriamente de bovinos jovens e adultos, maiores que um ano de idade, aparentemente
Quadro 1. Área, população bovina e produção anual de leite da mesorregião Norte Fluminense do estado do Rio de Janeiro

\begin{tabular}{lccc}
\hline Município estudado & $\begin{array}{c}\text { Área } \\
\text { (ha) }\end{array}$ & $\begin{array}{c}\text { População } \\
\text { bovina }\end{array}$ & $\begin{array}{c}\text { Produção de } \\
\text { leite (x 1000 L) }\end{array}$ \\
\hline Campos & 289.042 & 216.751 & 32.168 \\
Macaé & 110.760 & 89.408 & 10.703 \\
São Fidélis & 74.579 & 64.041 & 17.014 \\
Carapebus & $-a$ & - & - \\
Quissamã & 40.682 & 18.100 & 567 \\
Conceição de Macabú & 22.073 & 24.935 & 4.216 \\
São Francisco de Itabapoana & - & - & - \\
Cardoso Moreira & 27.056 & 24.324 & 5.403 \\
São João da Barra & 99.006 & 80.906 & 11.737 \\
Total & 663.198 & 518.465 & 81.806 \\
\hline
\end{tabular}

aMunicípios novos, não há dados estatísticos disponíveis pelo CIDE (1997).

sadios, puros Bos indicus ou mestiço B. indicus x B. taurus. O tamanho da amostra foi determinado, por conveniência e facilidade de acesso à propriedade, tomando como parâmetro a coleta de no mímino um número maior ou igual a $0,1 \%$ da população total de bovinos da mesorregião. Coletou-se, assepticamente, o sangue de 532 animais por venopunção jugular e, os soros obtidos foram aliquotados em tubos tipo Eppendorf e armazenados à $-20^{\circ} \mathrm{C}$ até $\mathrm{o}$ momento da análise sorológica.

As 532 amostras de soro coletadas estão distribuídas entre nove municípios com a seguinte amostragem: Campos $(n=186)$, Macaé $(n=91)$, São Fidélis $(n=55)$, Carapebus $(n=10)$, Quissamã $(n=50)$, Conceição de Macabú $(n=27)$, São Francisco de Itabapoana $(n=69)$, Cardoso Moreira $(n=25)$ e São João da Barra $(n=19)$. Os animais estudados foram divididos por grupos; quanto à faixa etária: 1 a 3 anos $(n=110), 3$ a 6 anos $(n=241)$ e $>6$ anos $(n=181)$; quanto ao sexo: fêmeas $(n=497)$ e machos $(n=35)$ e quanto à aptidão zootécnica: animais com aptidão zootécnica para corte $(n=444)$ e animais com aptidão zootécnica para leite $(n=88)$.

\section{Ensaio imunoenzimático (ELISA) indireto}

Realizou-se o ensaio ELISA indireto para detecção de anticorpos da classe IgG anti Babesia bigemina, utilizando-se microplacas de 96 orifícios para titulação. As microplacas foram sensibilizadas com extrato total antigênico de $B$. bigemina, obtido segundo técnica descrita por Madruga et al. (1997a), diluído em tampão carbonato pH 9,6. Os soros controles negativo e positivo, bem como os soros testes foram diluídos à 1:500 em tampão salino fosfatado com Tween 20 a $0,05 \%$ (PBST) $\mathrm{pH} \mathrm{7,4.} \mathrm{Adicionou-se} \mathrm{às} \mathrm{placas} \mathrm{conjugado} \mathrm{IgG} \mathrm{de}$ coelho anti IgG bovina marcada com fosfatase alcalina (Sigma Chemical) diluído em PBST pH 7,4. Utilizou-se como substratocromógeno para-nitrofenil fosfato (Sigma Chemical) diluído em tampão glicina $\mathrm{pH}$ 10,5. A leitura do ensaio foi realizada em espectrofotômetro multicanal para microplacas de 96 orifícios (Bio Rad Laboratories, model 550 Microplate Reader) ao comprimento de onda de $405 \mathrm{hm}$.

\section{Análise estatística}

Procedeu-se a análise estatística dos dados utilizando os testes de Fisher e Qui-quadrado $\left(\chi^{2}\right)$ com graus de confiança variando de acordo com o tipo de comparação. Para o ELISA a linha de corte (cutoff) foi estabelecida com o grau de confiança de $99,99 \%$.

\section{RESULTADOS}

A análise soroepidemiológica das 532 amostras de soros revelou que $371(69,74 \%)$ foram reagentes positivas ao ELISA 
indireto, com anticorpos da classe $\operatorname{IgG}$ anti Babesia bigemina, dos quais: $32,33 \%$ com título de $1: 500,22,56 \%$ com título de $1: 1000,10,90 \%$ com título de $1: 2000,3,38 \%$ com título de $1: 4000,0,38 \%$ com título de $1: 8000,0,19 \%$ com título de 1:16000 e 30,26\% foram negativos (Quadro 2).

A análise segundo a faixa etária, dividida em três grupos, revelou a prevalência relativa de $73,64 \%, 69,30 \%$ e $67,95 \%$ soropositivos, respectivamente, para os grupos de 1 a 3 anos, 3 a 6 anos e $>6$ anos de idade. Não houve diferença significativa entre os grupos etários $(P>0,05)$, segundo o teste $\chi^{2}$ (Quadro 3).

Quadro 2. Prevalência sorológica de anticorpos anti Babesia bigemina em bovinos $(\mathrm{n}=532)$ da mesorregião Norte Fluminense, determinada pelo ELISA indireto

\begin{tabular}{|c|c|c|c|c|}
\hline \multirow[t]{2}{*}{ Título } & \multirow{2}{*}{$\begin{array}{c}\text { Positivos } \\
\text { (n) }\end{array}$} & \multicolumn{2}{|c|}{ Prevalência } & \multirow{2}{*}{$\begin{array}{c}\text { Negativos } \\
\text { (n) }\end{array}$} \\
\hline & & Relativa & Absoluta & \\
\hline $1: 500$ & 172 & $46,36 \%$ & $32,33 \%$ & - \\
\hline $1: 1000$ & 120 & $32,35 \%$ & $22,56 \%$ & 一 \\
\hline $1: 2000$ & 58 & $15,63 \%$ & $10,90 \%$ & - \\
\hline $1: 4000$ & 18 & $4,85 \%$ & $3,38 \%$ & - \\
\hline $1: 8000$ & 2 & $0,54 \%$ & $0,38 \%$ & - \\
\hline 1:16000 & 1 & $0,27 \%$ & $0,19 \%$ & - \\
\hline Total positivos & 371 & $100 \%(371 / 371)$ & $69,74 \%(371 / 532)$ & - \\
\hline Total negativos & - & - & $30,26 \%(161 / 532)$ & 161 \\
\hline
\end{tabular}

Quadro 3. Prevalência sorológica de anticorpos anti Babesia bigemina em bovinos $(\mathrm{n}=532)$, segundo a faixa etária, da mesorregião Norte Fluminense

\begin{tabular}{ccccccc}
\hline & \multicolumn{5}{c}{ Faixa etária (anos) } \\
\cline { 2 - 7 } & $1-3(\mathrm{n}=110)^{\mathrm{a}}$ & \multicolumn{2}{c}{$3-6(\mathrm{n}=241)^{\mathrm{a}}$} & \multicolumn{2}{c}{$>6(\mathrm{n}=181)^{\mathrm{a}}$} \\
\cline { 2 - 8 } Positivo & $73,64 \%$ & $15,23 \%$ & $69,30 \%$ & $31,39 \%$ & $67,95 \%$ & $23,12 \%$ \\
& Relativa & Absoluta & Relativa & Absoluta & Relativa & Absoluta \\
Negativo & $26,36 \%$ & $5,45 \%$ & $30,70 \%$ & $13,91 \%$ & $32,05 \%$ & $10,90 \%$ \\
& $(29 / 110)$ & $(29 / 532)$ & $(74 / 241)$ & $(74 / 532)$ & $(58 / 181)$ & $(58 / 532)$ \\
Total & $100 \%$ & $20,68 \%$ & $100 \%$ & $45,30 \%$ & $100 \%$ & $34,02 \%$ \\
& $(110 / 110)$ & $(110 / 532)$ & $(241 / 241)$ & $(241 / 532)$ & $(181 / 181)$ & $(181 / 532)$
\end{tabular}

aNão houve diferença significativa $(P>0,05)$ entre as faixas etárias, segundo o teste $\chi^{2}$.

Quadro 4. Prevalência sorológica de anticorpos anti Babesia bigemina em bovinos $(\mathrm{n}=532)$, segundo a aptidão zootécnica, da mesorregião Norte Fluminense

\begin{tabular}{lcccc}
\hline & \multicolumn{4}{c}{ Aptidão zootécnica } \\
\cline { 2 - 5 } & \multicolumn{2}{c}{ Corte $(\mathrm{n}=444)^{\mathrm{a}}$} & \multicolumn{2}{c}{ Leite $(\mathrm{n}=88)^{\mathrm{a}}$} \\
\cline { 2 - 5 } & Relativa & Absoluta & Relativa & Absoluta \\
\hline \multirow{3}{*}{ Positivo } & $68,47 \%$ & $57,14 \%$ & $76,14 \%$ & $12,59 \%$ \\
& $(304 / 444)$ & $(304 / 532)$ & $(67 / 88)$ & $(67 / 532)$ \\
Negativo & $31,53 \%$ & $26,32 \%$ & $23,86 \%$ & $3,95 \%$ \\
& $(140 / 444)$ & $(140 / 532)$ & $(21 / 88)$ & $(21 / 532)$ \\
Total & $100 \%$ & $83,46 \%$ & $100 \%$ & $16,54 \%$ \\
& $(444 / 444)$ & $(444 / 532)$ & $(88 / 88)$ & $(88 / 532)$
\end{tabular}

aNão houve diferença significativa $(P>0,05)$ entre as aptidões zootécnicas, segundo o teste $\chi^{2}$ e o teste de Fisher.
Quadro 5. Prevalência sorológica de anticorpos anti Babesia bigemina em bovinos $(\mathrm{n}=532)$, segundo o sexo, da mesorregião Norte Fluminense

\begin{tabular}{lcccc}
\hline & \multicolumn{3}{c}{ Sexo } \\
\cline { 2 - 5 } & \multicolumn{2}{c}{ Fêmea $(\mathrm{n}=497)^{\mathrm{a}}$} & \multicolumn{2}{c}{ Macho $(\mathrm{n}=35)^{\mathrm{a}}$} \\
\cline { 2 - 5 } & Relativa & Absoluta & Relativa & Absoluta \\
\hline \multirow{2}{*}{ Positivo } & $69,82 \%$ & $65,22 \%$ & $68,57 \%$ & $4,51 \%$ \\
& $(347 / 497)$ & $(347 / 532)$ & $(24 / 35)$ & $(24 / 532)$ \\
Negativo & $30,18 \%$ & $28,20 \%$ & $31,43 \%$ & $2,07 \%$ \\
& $(150 / 497)$ & $(150 / 532)$ & $(11 / 35)$ & $(11 / 532)$ \\
Total & $100 \%$ & $93,42 \%$ & $100 \%$ & $6,58 \%$ \\
& $(497 / 497)$ & $(497 / 532)$ & $(35 / 35)$ & $(35 / 532)$
\end{tabular}

anão houve diferença significativa $(P>0,05)$ entre os sexos, segundo o teste $\chi^{2}$ e $o$ teste de Fisher.

A análise estatística, segundo a aptidão zootécnica revelou a soroprevalência de $68,47 \%$ de positivos para os bovinos com aptidão para corte e $76,14 \%$ de soropositivos para os bovinos com aptidão para leite. Não houve diferença significativa entre as aptidões zootécnicas $(P>0,05)$ pelo teste $\chi^{2}$ e pelo teste de Fisher (Quadro 4).

Em relação a soroprevalência segundo o sexo, não houve diferença significativa $(P>0,05)$ pelo teste $\chi^{2}$ e pelo teste de Fisher, onde $69,82 \%$ das fêmeas e $68,57 \%$ dos machos foram reagentes positivos (Quadro 5 ).

A prevalência comparada entre os nove municípios diferiu significativamente $(P<0,0001)$ segundo o teste $\chi^{2}$, onde os animais dos municípios: Campos 67,20\% (125), Macaé 85,72\% (78), São Fidélis 69,09\% (38), Carapebus 100\% (10), Quissamã 74\% (37), Conceição de Macabú 51,85\% (14), São Francisco de Itabapoana 69,57\% (48), Cardoso Moreira $32 \%$ (8) e São João da Barra $68,42 \%$ (13) foram soropositivos (Fig. 1).

\section{DISCUSSÃO}

A soroprevalência encontrada no presente estudo está abaixo do limite $(75,0 \%)$ para se considerar uma área como estável enzooticamente (Mahoney 1975). Sendo esta região considerada, portanto, uma área de instabilidade enzoótica, ou uma área que tende para uma zona marginal (Mahoney 1975, Leite et al. 1989). Embora existam fatores de resistência natural à babesiose (Levy et al. 1982) e a taxa de inoculação de Babesia bigemina por Boophilus microplus seja naturalmente alta (Mahoney 1967), a babesiose clínica poderia ocorrer nesta região em quaisquer grupo etário estudado. No entanto, nesta mesorregião o perfil da pecuária bovina é predominantemente de corte, constituída na sua maioria por raças de origem indiana (B. indicus) e seus mestiços (CIDE 1997), naturalmente resistentes a $B$. microplus e a Babesia spp. (Madruga et al. 1984a,b), fatos que justificam e asseguram que a doença clínica seja rara.

A diferença estatística observada na mesorregião Norte Fluminense, quanto a prevalência de positivo, implica inferir que em alguns municípios desta área existe a possibilidade de risco da ocorrência de surtos de babesiose, pois a infecção por $B$. bigemina em bovinos não é homogênea entre os municípios. Prevalências entre 12 a $75 \%$ significam que os 


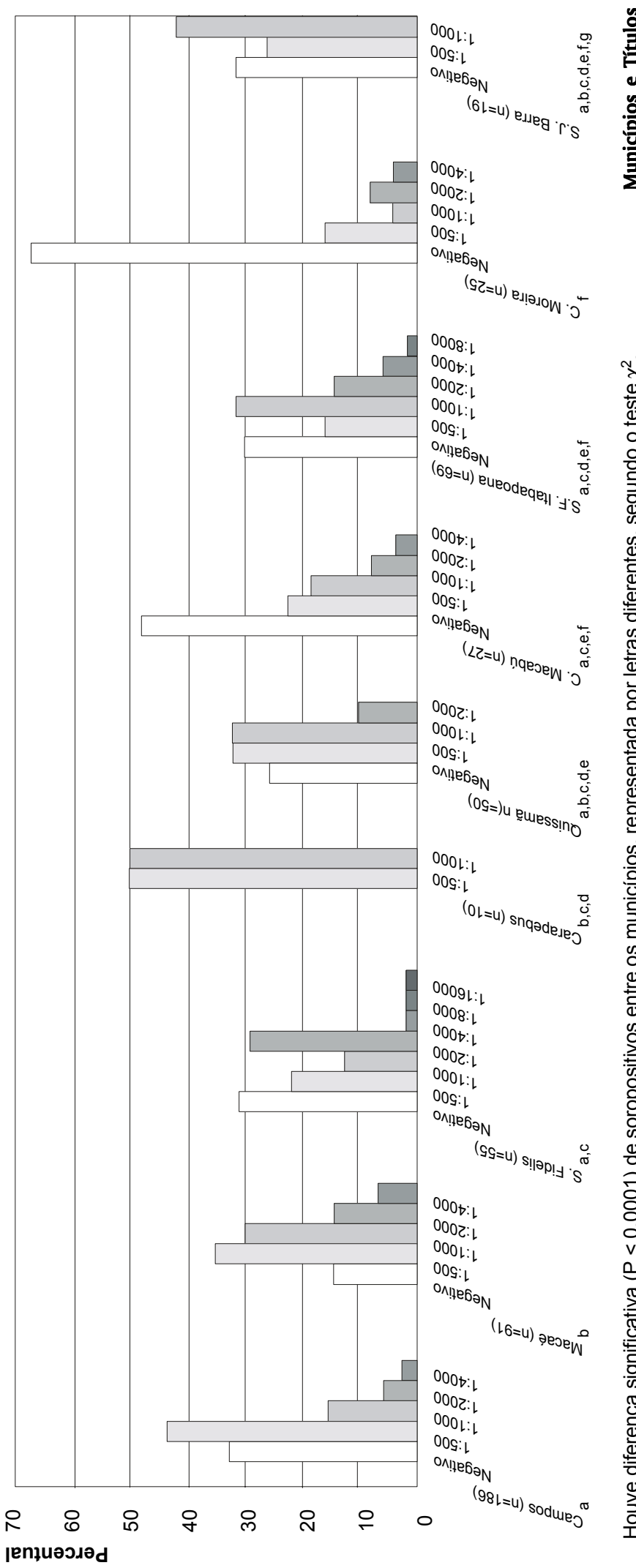

Fig 1. Prevalência de anticorpos anti Babesia bigemina em bovinos $(n=532)$ da mesorregião Norte Fluminense. Distribuição segundo os municípios estudados animais se infectam antes de um ano de idade, quando são mais resistentes aos hemoparasitos e, um número variável de animais adultos apresenta babesiose clínica (Mahoney \& Ross 1972, Madruga et al. 1984b). Resta-nos o conhecimento da infecção em bezerros a fim de averiguar os níveis de anticorpos colostrais e anticorpos de primo-infecção.

Os resultados obtidos no presente trabalho são inferiores àqueles registrados em outros estados de diferentes regiões do país, onde predominam áreas de estabilidade enzoótica para $B$. bigemina. Em um estudo realizado na Zona da Mata do estado de Minas Gerais a prevalência de anticorpos anti $B$. bigemina foi de 79,0\% (Patarroyo et al. 1987), determinada pela prova de imunofluorescência indireta (IFI). No estado de Goiás o percentual de positividade observada foi de $97,5 \%$ (Linhares et al. 1992), enquanto no estado de Pernambuco foi de $87,9 \%$ (Alves 1987), ambas determinadas pela IFI. Madruga et al. (1997b) verificaram que, tanto em áreas de estabilidade quanto de instabilidade enzoótica, o ELISA indireto mostrou-se com especificidade e sensibilidade iguais ou superiores à IFI. No entanto, o ELISA é mais adequado para estudos soroepidemiológicos por garantir maior amplitude de titulação.

A não observação de diferença estatística segundo a aptidão zootécnica e segundo o sexo, na mesorregião estudada, faz inferir que independente destes parâmetros a infecção, nos bovinos por $B$. bigemina, é baixa ( $<75 \%$ de soropositivos) e todos os grupos analisados estão sujeitos à casos clínicos de babesiose.

Os presentes resultados indicam que nesta circunstância epidemiológia justifica-se o controle da enfermidade com o acompanhamento sorológico para identificação dos animais expostos à condição de risco (Mahoney \& Ross 1972, Mahoney 1975). Sendo necessário, nesta situação, possivelmente, a imunização de animais nativos, além de animais importados de outras áreas ou regiões.

Na mesorregião Norte Fluminense do estado do Rio de Janeiro a infecção por $B$. bigemina é baixa a moderada, fenômeno que faz caracterizá-la como área sujeita ao desequilíbrio epidemiológico. A técnica ELISA indireto utilizada mostrouse adequada na detecção e diferenciação dos níveis de anticorpos anti $B$. bigemina em bovinos da mesorregião estudada.

\section{REFERÊNCIAS}

Alves L.C. 1987. Prevalência de babesiose em gado leiteiro no município de Garanhuns, estado de Pernambuco. Tese de Mestrado, FMVZ-USP, São Paulo. $124 \mathrm{p}$.

Araújo F.R., Madruga C.R., Leal C.R.B., Schenk M.A.M., Kessler R.H., Marques A.P.C. \& Lemaire D.C. 1998. Comparison between enzyme-linked immunosorbent assay, indirect fluorescent antibody and rapid conglutination tests in detecting antibodies against Babesia bovis. Vet. Parasitol. 74:101-108.

MARA 1985. Carrapato, berne e bicheira no Brasil. Secretaria de Defesa Sanitária Animal, Ministério da Agricultura e Reforma Agrária (MARA), Brasília. $153 p$.

CIDE 1997. Território, Rio de Janeiro. Fundação de Informação e Dados do Rio de Janeiro. 80p.

Leite A.M.O., Arnoni J., Silva S.S., Farias N., Cruz H. \& Nishikawa H. 1989. Serological study of bovine babesiosis in a marginal area of Brasil. Proc. 
8th National Veterinary Hemoparasite Disease Conference, St. Louis, p. 624-635.

Levy M.G., Clabaugh G. \& Ristic M. 1982. Age resistance in bovine babesiosis: role of blood factors in resistance to Babesia bovis. Infect. Immun. 37(3):11271131.

Linhares G.F.C., Massard C.L., Araújo J.L.B. \& Alves L.C. 1992. Levantamento sorológico para Babesia bigemina (Smith \& Kilborne, 1893) e Babesia bovis (Babés, 1888) em bovinos da região Centro-Oeste do Brasil. Arq. Univ. Fed. Rural do Rio de Janeiro 15:85-91.

Madruga C.R., Gomes R.F. \& Schenk M.A.M. 1984a. Etiologia de algumas doenças de bezerros de corte no estado de Mato Grosso do Sul. Circular Técnica 15, Embrapa-CNPGC, Campo Grande, MS. 27p.

Madruga C.R., Aycardi E., Kessler R.H., Schenk M.A.M. \& Figueiredo G.R. 1984b. Níveis de anticorpos anti Babesia bigemina e Babesia bovis, em bezerros da raça nelore, ibagé e cruzamentos de nelore. Pesq. Agropec. Bras. 19(9):11631168.

Madruga C.R., Schenk M.A.M., Kessler R.H. \& Miguita M. 1997a. Desenvolvi- mento de um teste de imunoadsorção enzimática (ELISA) para deteç̧ão de anticorpos contra Babesia bigemina. Revta Bras. Parasitol. Vet. 6 (Supl.1):304.

Madruga C.R., Marques A.P.C., Queiroz R.A. \& Vaz E.C. 1997b. Avaliação de um teste ELISA para detecção de anticorpos contra Babesia bigemina em bovinos de áreas de estabilidade e instabilidade enzoótica. Revta Bras. Parasitol. Vet. 6 (Supl.1):302.

Mahoney D.F. 1967. Bovine babesiosis: preparation and assessment of complement fixing antigens. Exp. Parasitol. 20: 232-241.

Mahoney D.F. 1975. The diagnosis of babesiosis in Australia, p.49-62. In: Wells E.A. (ed.) Workshop on Hemoparasites (Anaplasmosis and Babesiosis). CIAT, Cali, Colombia.

Mahoney D.F. \& Ross D.R. 1972. Epizootiological factors in the control of bovine babesiosis. Aust. Vet. J. 48:292-298.

Patarroyo J.H., Ribeiro M.F.B. \& Santos J.L. 1987. Epidemiologia das babesioses bovinas no estado de Minas Gerais I. Prevalência de anticorpos fluorescentes na "Zona da Mata”, MG. Arq. Bras. Med. Vet. Zootec. 39:423-429. 